\title{
O difícil encontro da justiça com a educação: problematizações sobre a justiça restaurativa
}

\author{
Flávia Schilling ${ }^{1}$ \\ ORCID: 0000-0001-5126-8507 \\ Daniele Kowalewski ${ }^{1}$ \\ ORCID: 0000-0002-2684-7504
}

\section{Resumo}

$\mathrm{Na}$ pesquisa ${ }^{2}$ que dá origem a este artigo, ao lado do estudo das formas do saber sobre a relação densa e tensa entre justiça e educação, exploramos a vertente das matrizes normativas expressas em políticas públicas que propõem a introdução da justiça restaurativa nas escolas de São Paulo. Neste artigo, trabalharemos esta vertente a partir da análise de dois documentos formativos sobre práticas de justiça restaurativa, explorando visões de conflito, violência, mediação, casos a serem atendidos e expectativas de transformação do cotidiano escolar. Foram feitas oito entrevistas com professores/as de duas escolas municipais que estavam recebendo o projeto e passaram pela formação analisada. Em seus depoimentos, destaca-se a raridade de casos de violência relatados e como a justiça restaurativa é mais compreendida como mediação de conflitos e uma forma de se trabalhar com a disciplina nas escolas. Todas as entrevistas citam o respeito como principal meta dessa forma de justiça, definida como esperança de melhora no convívio. A intenção foi a de verificar os contornos da política na visão dos seus sujeitos e o quanto a formalização da microjustiça - na forma de justiça restaurativa - potencializa (ou não) a possibilidade de se pensar em uma escola justa.

\section{Palavras-chave}

Educação - Justiça restaurativa - Conflitos - Direitos humanos.

1 - Universidade de São Paulo. São Paulo, SP, Brasil. Contatos: flaviaischilling@gmail.com; danielesociologia@gmail.com.

2- Justiça, direitos humanos e violência: a escola justa e as práticas da justiça restaurativa no marco do Programa justiça e educação (CNPq 2013-2016, Bolsa PQ1C).

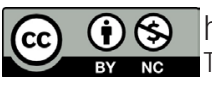




\section{The difficult encounter between Justice and Education: discussions about restorative justice}

\section{Abstract}

In the research which this paper is based upon, alongside a study concerning the potential means of learning about the tense and dense relationship between justice and education, we explore the normative matrices arising from public policies that have introduced Restorative Justice in schools in the City of São Paulo. This paper discusses these normative matrices using two foundational documents on Restorative Justice practices, exploring views of conflict, violence, mediation, types of cases, and expectations regarding changes in the school's everyday life. For this purpose, eight interviews with teachers from two local schools where these projects were implemented have been carried out. In their testimonies, the lack of cases of violence is noteworthy, as well as how Restorative Justice is understood as a mechanism of conflict mediation and a way to deal with discipline at schools. All the interviewees mention that respect is the main purpose of this type of Justice, defined as hope for a better school environment. The goal was to understand the scope of the policies as seen by the individuals involved, as well as how much formalizing micro-justice - in the form of Restorative Justice - boosts (or not) the possibilities of considering the idea of a fair school.

\section{Keywords}

Education - Restorative justice - Conflicts - Human rights.

\section{Introdução}

0 projeto de pesquisa Justiça, direitos humanos e violência: a escola justa e as práticas da justiça restaurativa no marco do programa justiça e educação buscou analisar algumas iniciativas dos últimos anos, que aproximaram a educação e seu sistema escolar com a justiça e suas instituições e experiências. 0 contexto destas iniciativas não deve ser esquecido: o grande marco é o da luta pela democratização do país, pelo respeito aos direitos humanos e pela construção de formas mais justas de vivermos juntos. Claramente inseridos em um contexto de promoção de direitos, de respeito aos direitos humanos e ao ECA, na democratização do país, esses esforços generosos merecem ser analisados e ter sua memória mantida. Pois esta é a situação que não podemos ignorar: nestes anos passados, vivemos muitas experiências de grande importância que apontaram para caminhos inovadores e possíveis para termos uma sociedade mais justa. Estas experiências, projetos, reflexões, mesmo pertencentes a um passado muito recente, sofrem com o apagamento da memória característico do país. Este artigo apresenta, assim, um esforço para retomar, de forma analítica, possibilidades e limites das ideias em questão, em torno da sempre difícil relação entre educação e justiça. Como pensar uma escola justa, um sistema educacional justo? 
Como marcos para pensar estes estudos, cabe assinalar a importância da inclusão das leituras de Derrida (2007), Ewald (1993), Fraser (2008), Ricoeur (2008), Heller (1998), Arendt (2004), Bauman (2000), que são centrais no debate sobre justiça e o justo e que permearão as análises deste artigo (SCHILLING, 2014).

Ricoeur (2008) discorre longamente sobre a justiça como fazendo parte do conjunto de alternativas que a sociedade opõe à violência. A justiça se opõe tanto à violência aberta e reconhecida como à violência dissimulada e sutil, assim como à violência da vingança (RICOEUR, 2008, p. 179).

Tenta-se, neste texto que vai rumo às práticas formativas sobre a justiça restaurativa, seguir o conselho de Derrida (2007, p. 37):

É preciso ser justo com a justiça, e a primeira justiça a fazer-lhe é ouvi-la, tentar compreender de onde ela vem, o que ela quer de nós [...] é preciso também saber que essa justiça se endereça sempre a singularidades, à singularidade do outro, apesar ou mesmo em razão de sua pretensão à universalidade.

Fraser (2008) também nos auxilia centralmente, encarando a angústia que convive com a iniludível questão da justiça. Quais são as formas possiveis de praticar a justiça na era da globalização? Quando há o rompimento dos antigos marcos, aqueles que emolduram uma justiça "normal”? É a partir de suas análises sobre a balança e os mapas atuais da justiça que formulamos nossas perguntas tanto aos documentos formativos apresentados como aos sujeitos entrevistados.

Como já apresentado com detalhes em outro texto (SCHILLING, 2014), se julgar é deslindar para pôr fim à incerteza (RICOEUR, 2008, p. 175), como julgar na sociedade da incerteza? Nesse marco, há aquele que julga, que tem essa legitimidade. Há técnicas, meios que garantiriam o julgamento justo. Ricoeur já descreve, porém, o que chama um "mas", um intervalo, uma pausa que seria característica da justiça e da busca do justo. Se o justo se situa entre o legal e o bom, produzindo-se de acordo com as leis escritas, com a presença de um âmbito institucional bem definido na forma de tribunais e cortes de justiça, na atuação de pessoas qualificadas, encarregadas de julgar, com uma ação bem definida em termos de processo, seu âmago é apartar, separar. Para conseguir esse feito, diz, é preciso ir ao âmago do conflito, ver o que existe por trás do processo, do litígio, da pendência. Para ele, como pano de fundo do conflito, está a violência: "O lugar da justiça encontra-se assim marcado em negativo, como que fazendo parte do conjunto das alternativas que uma sociedade opõe à violência, alternativas que, ao mesmo tempo, definem um Estado de direito" (RICOEUR, 2008, p. 179).

Fraser (2008) trabalhará com as noções de mapa e balança para tentar equacionar quais seriam as escalas de justiça que nos garantiriam uma aproximação em direção a uma justiça justa. Trabalhando com os conceitos de redistribuição, reconhecimento e participação, enfrenta os dilemas colocados em relação a essas questões na sociedade póswestfaliana. Proporá pensar esses dilemas no marco da justiça anormal, pois não haveria mais concordância entre o que será objeto de disputa, quem (quais os atores) tem direito nessa disputa, quais as instituições que deverão garantir a justiça, no como se fará justiça. 
Trata-se de repensar o "quê" da justiça: está em questão o objeto da justiça; o "quem" da justiça: quem é o sujeito da justiça, seu destinatário principal?; o "como" da justiça: não haveria um acordo sobre como deveriam resolver-se as disputas e demandas sobre a gramática da justiça (SCHILLING, 2014).

São estes, portanto, alguns breves contornos teóricos sobre o tema da justiça e do justo que permitem compreender a necessidade de uma escuta do que se apresenta nos distintos planos que compõem uma política pública que pretende afetar a educação escolar.

É este segundo aspecto que será central neste artigo. Apresentaremos, neste texto, uma análise de um documento formativo criado no marco de uma política pública da SEE/São Paulo, o Programa justiça e educação: parceria para a cidadania, que propõe, entre outras medidas, a formação de professores/as mediadores/as e a justiça restaurativa nas escolas. Além deste documento precursor de uma política pública, trabalharemos com os materiais sobre justiça restaurativa formulados por uma ONG de reconhecida importância na cidade de São Paulo na temática e apresentaremos entrevistas com oito professores/as de duas escolas municipais da zona sul da cidade de São Paulo, participantes da formação oferecida pela ONG e que iniciavam um trabalho de implantação da proposta em suas escolas.

\section{Justiça e educação de mãos dadas? A introdução da justiça restaurativa ${ }^{3}$}

Analisaremos o material Justiça e educação em Guarulhos e Heliópolis: parceria para a cidadania, fruto da parceria entre os sistemas de educação e justiça e parte dos materiais para a implementação do projeto de justiça restaurativa. Pode-se sugerir que se trata de material governamental precursor no âmbito da formação de professores em justiça restaurativa. Sem pretender esgotar a análise dos contornos destas iniciativas em torno da justiça restaurativa nas escolas ${ }^{4}$, nosso intuito é criar um contexto que dialogue com a pesquisa com os/as professores/as envolvidos/as na aplicação destas formas de resolução de conflitos.

Apresenta-se, inicialmente, o histórico da introdução da justiça restaurativa no país:

No Brasil, a Justiça Restaurativa foi introduzida formalmente em 2004, por meio do Ministério da Justiça, através de sua Secretaria da Reforma do Judiciário, que elaborou o projeto "Promovendo Práticas Restaurativas no Sistema de Justiça Brasileiro”, e, juntamente com o PNUD - Programa das Nações Unidas para o Desenvolvimento, apoiou três projetos-piloto de Justiça Restaurativa, sendo um deles no Estado de São Paulo, na Vara da Infância e da Juventude da Comarca de São Caetano do Sul. (EDNIR, 2007, p. 16-17).

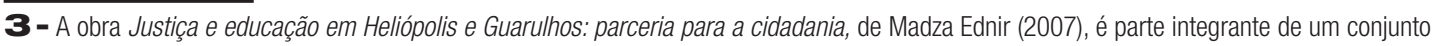
de materiais de registro de implementação do Projeto "Justiça e educação em Heliópolis e Guarulhos: parceria para a cidadania". Projeto da Fundação para o Desenvolvimento da Educação - FDE, executado pelo CECIP - Centro de Criação de Imagem Popular, com a participação dos Juízes das Varas da Infância e da Juventude de Guarulhos e Varas Especiais da Infância e da Juventude da Capital/SP. Ver também: Melo (2008) e Penido (2009).

4- Para uma análise ímpar do que é a justiça restaurativa, seu histórico, suas práticas, ver Boonen (2011).
} 
Há, assim, como já apontado, um movimento no sentido de implantação de práticas restaurativas em diversas situações no marco do poder judiciário brasileiro, com estas iniciativas se estendendo para outras realidades e instituições, como as escolas. Cabe indagar e problematizar essa transposição, de um sistema para outro, de uma instituição de justiça para uma de educação, suas possibilidades e seus limites. Este é um estudo que, no presente artigo, será apenas esboçado, mas deve ser objeto de futuras investigações. ${ }^{5}$

\section{“Quando justiça e educação querem andar de mãos dadas": conflitos e violência}

0 título do primeiro capítulo é sugestivo: "Quando Justiça e Educação querem andar de mãos dadas” (EDNIR, 2007, p. 9). Inicia-se, assim, o capítulo mostrando a construção de uma parceria. 0 motivo explícito para que esta parceria ocorra é o da violência nas escolas:

A violência é hoje a principal preocupação dos brasileiros; ela se manifesta na sociedade e, portanto, em suas instituições como, por exemplo, nas escolas; e as abordagens punitivas usadas para lidar com ela não têm funcionado. (EDNIR, 2007, p. 6).

0 capítulo traz uma primeira definição do que é violência em suas múltiplas dimensões. Não há, de fato, uma delimitação do que é a violência na escola, como esta se apresenta, quais são suas singularidades. Não há, também, dados sobre a violência que está percorrendo a escola. A primeira pergunta, portanto, quando analisamos a violência da/na escola é sempre a seguinte: de que violência estamos falando quando falamos em violência na escola? Como ir além das generalizações sem um diagnóstico do que, realmente, acontece?

Partindo deste pressuposto, o texto continua mostrando que há iniciativas de sucesso, nas redes escolares, de redução da violência. 0 modelo é o das cidades educadoras e da educação para a paz. Este modelo se sustenta em parcerias da escola com outros atores para a resolução não violenta de conflitos:

Do mesmo modo, aprender a resolver conflitos de modo cooperativo e não-violento, baseado numa ética de diálogo, tendo como objetivo a responsabilização coletiva e participativa de todos envolvidos, é também um grande desafio. 0 ato de se fazer justiça por meio do diálogo que esclarece e conscientiza e não por meio do julgamento, se apresenta também "subversivo" em relação à ideologia historicamente enraizada que se baseia no "poder sobre o outro" e não no "poder com o outro". (EDNIR, 2007, p. 12).

A justiça restaurativa tem um lugar importante nesta resolução não violenta de conflitos, por ser "[...] uma abordagem daquilo que foi quebrado por conflitos e de prevenção da violência [...]” (EDNIR, 2007, p. 13). É a possibilidade da relação com o outro. Se opõe à Justiça Retributiva e se apresenta como algo mais justo em relação a

5- Para compreender a justiça restaurativa no marco do sistema punitivo neoliberal, sugere-se a leitura de 0'Malley (2006). 
algo que é reconhecido como parcial e injusto. Seus valores permitem alcançar uma nova possibilidade de justiça:

Os valores que regem a Justiça Restaurativa são: empoderamento, participação, autonomia, respeito, busca de sentido e de pertencimento na responsabilização pelos danos causados, mas também na satisfação das necessidades emergidas a partir da situação de conflito. Esses valores têm demonstrado a possibilidade de se alcançar o restabelecimento do senso de justiça, dignidade e segurança - daí seu nome "restaurativa" - em termos diferentes daqueles que levaram à situação de conflito. (EDNIR, 2007, p. 13).

Na definição acima, a ênfase está em que a justiça restaurativa restaura o senso de justiça, dignidade e segurança. Há o esforço para colocar a prática restaurativa em um bom lugar, em um lugar alternativo ao que temos e que esta prática gerará mais justiça. Cabe mencionar que, neste primeiro momento, não se fala em transformação das relações em que o conflito foi gerado. Há a ideia de restaurar (uma ordem que foi quebrada). 0 documento, mais adiante, explicita a questão da transformação, tanto da escola como da comunidade, por meio das práticas de justiça mais justas da justiça restaurativa.

Assim, na Justiça Restaurativa há o encontro entre aquele que praticou o ato que gerou um dano ("autor do ato"), com aquele que recebeu este ato ("receptor do ato"), para que o primeiro se defronte com as consequências de suas escolhas e ações. Deste encontro, facilitado por pessoas capacitadas em técnicas de condução de conflitos, também participam pessoas que foram indiretamente atingidas pela ofensa e que possam contribuir para a resolução do conflito. Neste encontro, baseado numa ética de diálogo, visa-se, não a punição, mas a efetiva responsabilização. Visa-se que as causas que levaram ao ato danoso sejam investigadas, do mesmo modo que se reparem os danos e se lide, ainda, com as sequelas que brotaram a partir da ofensa. (EDNIR, 2007, p. 13).

Há, no Brasil, um quadro dramático que justifica a introdução de práticas restaurativas nas escolas.

Justiça e Educação, estendendo reciprocamente as mãos, certamente maximizam suas capacidades para atuar no sentido contrário à triste realidade social que vivemos. As experiências anteriores de Justiça Restaurativa, no Brasil e no mundo, mostram a viabilidade desta articulação, da qual dependem a própria reversão do quadro de deterioração de valores e do individualismo sem limites na luta por sobrevivência, com a construção de direitos de cidadania para todos. (EDNIR, 2007, p. 17).

Como reverter esse quadro de ausência de direitos, com graves problemas sociais e econômicos? Como contribuir para uma construção democrática em um país com pouca experiência em democracia? Estes são dilemas angustiados que percorrem o discurso apresentado no documento. Surge, assim, a necessidade de reverter uma realidade que se apresenta como de deterioração de valores e de individualismo sem limites ou em que há que construir novos valores, valores cooperativos e democráticos. 
Bauman (2000) trabalha centralmente esta questão contemporânea de uma crise ou dissolução (deterioração) de valores na digressão "Pós-modernidade e a crise moral e cultural". Propõe entender o termo "crise" como uma palavra que designa o momento de tomar decisões. Tem mais a ver com criterion do que com desastre ou catástrofe. Nos dias de hoje, significa um momento de ignorância e indecisão sobre o rumo das coisas, em que a confiança parece ficar em seu nível mais baixo, refletindo, talvez, algumas mudanças que estão acontecendo: a) agora as mudanças são muito rápidas e profundas; b) nunca antes os eventos que marcam as gerações envelheceram e desapareceram tão rápido e os períodos de tempo de gerações específicas são mais curtos do que nunca, com o número de gerações convivendo tendo aumentado - daí a polifonia (cacofonia) da cena pública e a dificuldade de comunicação; c) talvez esteja acontecendo uma mudança mais profunda e estamos usando um velho termo para expressar um novo tipo de ansiedade. Esse é o contexto da crise ou da percepção de uma deterioração dos valores. Bauman (2000, p. 147, grifo do autor) propõe que "[...] a crise, na medida em que a noção se refere à invalidação de jeitos e maneiras costumeiros e à resultante incerteza sobre como prosseguir, é o estado normal da sociedade humana".

Concordamos com o momento da crise sendo um momento ímpar para a tomada de decisões, para se tentar outros modos de viver. No caso que analisamos, a proposta passa por modos mais cooperativos e democráticos. Cabe também mencionar que, assim como o estado de crise é o estado normal das sociedades humanas, os conflitos estão presentes em qualquer instituição. Entender o que os gera, como se manifestam, o que provocam, a quem envolvem é a questão que permite pensar em boas e, talvez, inovadoras práticas.

\section{A transformação de escolas e comunidades}

O Projeto Justiça e Educação tem como visão contribuir para a transformação de escolas e comunidades, que vivenciam situações de violência, em espaços de diálogo e resolução pacífica de conflitos [...]. 0 que se busca é tornar a Justiça mais educativa e a educação mais justa. Para tanto, estimula-se o entendimento de que as ações educativas extrapolam o âmbito da escola, são sugeridos procedimentos que facilitam a atuação de forma sistêmica e as manifestações de violência são investigadas a partir de suas causas [...]. Essa investigação é função tanto da educação como da justiça, respeitando suas especificidades técnicas, e tendo em vista a realização do que está previsto no ECA. (EDNIR, 2007, p. 26).

Este é o ponto central da nossa investigação: o que se busca é tornar a justiça mais educativa e a educação mais justa. Aparece a ideia de que haverá uma transformação de escolas e comunidade e também uma transformação das instituições do poder judiciário envolvidas. É um trabalho que vai além das transformações individuais, ou da simples restauração de uma ordem que gera, em última instância, os conflitos que podem se manifestar de forma violenta.

Há um novo termo que surge no documento, emoldurando as ações: "Este projeto é uma possibilidade de criar um espaço para se articular a reflexão sobre o trabalho com direitos humanos nas escolas com as questões do poder, da violência e da autoridade" 
(EDNIR, 2007, p. 35). Essa é uma nova formulação que mostra quão pertinente é esta análise para o presente projeto de pesquisa. Como se articulam os direitos humanos, a violência, as questões do poder e da autoridade democráticas? ${ }^{6}$

0 documento continua introduzindo a seguinte questão:

É possível que a maior parte das situações de incivilidades, conflitos e violências praticadas por adolescentes, que também são alunos de escolas da rede pública, sejam acompanhados por um trabalho de intervenção com a possibilidade de construção, mediação e restauração de relações de poder democráticas. Essa intervenção é um canal para a resolução não-violenta de conflitos e para o não apagamento do outro. (EDNIR, 2007, p. 35).

Novamente, o objetivo é claramente traçado: trata-se de estabelecer - restaurar? - relações de poder democráticas. Há, também, uma hipótese da inter-relação entre incivilidade, conflito e violência. Não fica claro, porém, quais são os conflitos que aparecem sob a forma de incivilidades ou violência. Aqui os três termos aparecem equiparados e numa íntima relação. Chamamos a atenção para este tópico, pois daqui emergirão os sujeitos que serão escolhidos para as práticas restaurativas. Considerando que há conflitos entre a escola e o território, conflitos entre a escola e famílias, conflitos entre adultos da escola, conflitos entre alunos, conflitos entre professores e alunos... quem será objeto das ações de restauração?

\section{Os casos da justiça restaurativa}

Cabe, assim, citar o documento, no tópico chamado "Círculos Restaurativos nas escolas: a perspectiva da Justiça":

Decidiu-se pela realização de Círculos Restaurativos nas unidades escolares nos casos de infrações meramente disciplinares (desentendimento, rebeldia) ou atos infracionais de natureza leve. ${ }^{7}$ [... importante ressaltar que, em todas as hipóteses, o adolescente será tratado com respeito e dignidade e terá todos os seus direitos preservados, conforme determina o Estatuto da Criança e do Adolescente. (EDNIR, 2007, p. 50).

0 perfil da população a ser atendida será, assim, aquela composta por casos disciplinares e infracionais de natureza leve e tratará dos adolescentes. Não há um cuidado em estabelecer, nesses casos disciplinares, quais tipos de "desentendimento" ou "rebeldia" serão objeto de atenção. Há, assim, uma gama muito ampla de comportamentos que poderão ser enquadrados nestas categorias e encaminhados aos círculos.

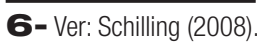

7- Consideram-se infrações leves aquelas equiparadas aos delitos de menor potencial ofensivo, ou seja, delitos para os quais a pena máxima não seja superior a 01 (um) ano ou, mesmo que exceda a um ano, não tenham graves consequências. Assim é que, por exemplo, homicídio tentado ou consumado, roubo, sequestro, extorsão, estupro, atentado violento ao pudor, porte de arma, tráfico de entorpecentes são qualificados como infrações graves. Já atos infracionais como agressões sem lesões, injúria, pichação, desacato a funcionário público, dano ao patrimônio público são tidos como leves e passíveis de abordagem por meio de Círculo Restaurativo. (EDNIR, 2007, p. 50). 
Novamente chamamos a atenção para o fato de que, quando não há uma clara definição do que é violência no ambiente escolar, do que acontece em sala de aula, das diferenças entre incivilidades, indisciplina e violência, abre-se margem para uma atuação que leva a uma criminalização ampla de comportamentos. É esta a questão central que paira sobre o encontro da justiça e da educação, permeada por boas intenções, mas que pode levar a um hipercontrole de condutas, como nunca visto. De todos os conflitos que acontecem no cotidiano escolar, seriam o objeto da ação da justiça restaurativa aqueles praticados por adolescentes e ligados à indisciplina.

\section{“Reconhecer, responsabilizar-se, restaurar"}

Há outro material importante produzido, desta vez por uma organização não governamental que desenvolve um trabalho pioneiro com a justiça restaurativa em São Paulo, o CDHEP (2014). ${ }^{8}$ Trazemos alguns elementos deste texto para contextualizar as entrevistas com professores que participaram da formação do CDHEP em 2015.

0 conteúdo apresentado nesta publicação, fruto de uma ação conjunta entre a Secretaria Nacional de Direitos Humanos (SDH), em parceria com as Varas de Infância e Juventude (VIJ) de São Paulo e São Caetano do Sul (SCS), Coordenadoria da Infância e da Juventude (CIJ) do Tribunal de Justiça de São Paulo (TJSP), Ministério Público (MP) e Associação Brasileira de Magistrados (ABM), Promotores de Justiça e Defensores Públicos da Infância e Adolescência, relata com detalhes os passos, entreves e resultados das ações realizadas em São Caetano do Sul e Campo Limpo.

0 texto apresenta a seguinte epígrafe:

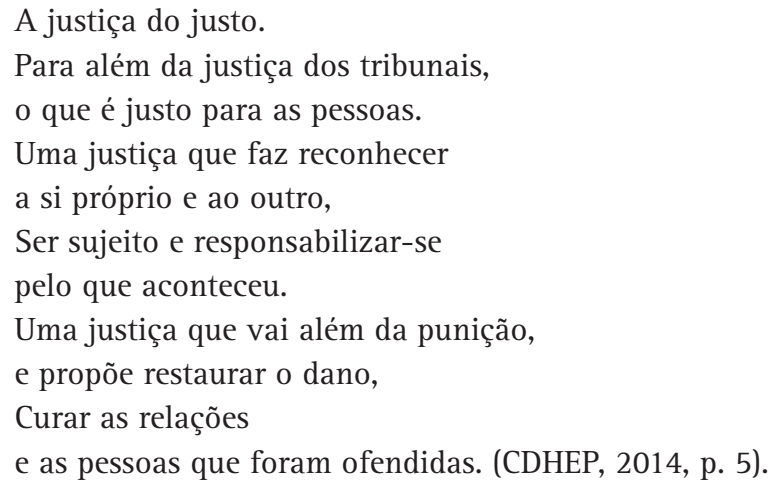

Na apresentação, encontramos a seguinte afırmação:

Uma das perguntas que perpassa o relatório é sobre a possibilidade de configurar a convivência para que todos se responsabilizem pelos seus atos e omissões - Estado, famílias, comunidades e jovens. [...] aparecem faltas e erros, abusos e despreparos de agentes que têm como missão proteger os adolescentes e jovens e ajudá-los a crescer para se tornarem cidadãos plenos. Sabemos que este

8- Ver também Boonen (2011). 
caminho é longo e pede muita formação e educação. E cidadania de todos. Deixar aparecerem as falhas, tal como aparecem, é um ato de coragem do Centro de Direitos Humanos e Educação Popular. [...] nosso desejo é que este relatório seja um convite para que novos personagens sigam adiante na tarefa de restaurar a justiça, o que pede, concomitantemente, a instauração de direitos sobretudo, os sociais básicos que garantem a proteção da infância e juventude. (CDHEP, 2014, p. 6-7).

Este relatório traz práticas de justiça restaurativa em seus impasses, limites e possibilidades. É um material muito diferenciado e que nos leva a pensar que o campo da justiça restaurativa está longe de ser um campo uniforme e estável e se configura claramente como um campo de luta perpassado por diferentes visões. A polifonia de vozes e as tensões são o que constituem o diferencial do material. Não há a ideia de que os círculos ou conferências restaurativas produzam, necessariamente, uma mudança ou uma transformação. Esta se apresenta muitas vezes restrita a uma possibilidade de um estar em determinado mundo de uma outra forma, pelo menos por algum tempo. Se há o reconhecimento de seus limites, há a clareza de que outras transformações são necessárias: nas instituições, na real proteção à infância e à adolescência, no respeito aos direitos sociais e civis.

Cumpre observar que, neste material, o foco são menores infratores que estão nas escolas. Trata de casos que percorreram o circuito do sistema de justiça e que, em um momento, tiveram o apoio do círculo. Em todos, vale observar a dimensão da importância da família dos envolvidos (com a justiça restaurativa por momentos parecendo um trabalho terapêutico familiar, restaurando - ou melhor, criando - certos laços familiares), a dificuldade do trabalho com a vítima (posta como elemento central que justifica em grande parte a justiça restaurativa pela possibilidade de reparação do dano) e a dimensão comunitária, a mais difícil de modificar, pois signifıca mudar imagens cristalizadas sobre os agressores.

Além do relato minucioso do desenvolvimento dos casos, há um capítulo sobre "Aprendizados e recomendações”, que merece ser destacado.

A experiência de Círculo/Conferência - compartilhar uma situação para construir caminhos para a superação de um conflito ou dificuldade, em geral, foi valorizada, sugerindo ganhos na possibilidade de escuta, na abertura para a alteridade e na desconstrução de significados cristalizados. Sensibilização, planejamento e preparo são indispensáveis para não correr o risco de desarticulação e retraumatização. (CDHEP, 2014, p. 125).

Há três elementos significativos, apontados no relatório, que mostram a importância e possibilidade da justiça restaurativa: o primeiro elemento apresentado é a escuta. Já marcamos nosso questionamento sobre se a escola não seria, ela, um lugar de escuta, de diálogo entre professores e alunos: aparentemente, esta possibilidade não existe de forma geral. 0 segundo elemento apontado é o da abertura para a alteridade. 0 outro, aquele que é diferente em algum aspecto de mim, encontra uma possibilidade de ser visto e ouvido, percebido como alguém com quem compartilho algumas características, principalmente a da possibilidade da 
palavra. 0 "fechamento" à alteridade, como já exposto, é uma das questões que subjaz aos conflitos nas escolas. É uma das demandas na construção da escola justa, encontrada em nossa pesquisa sobre o tema, que exige respeito à igualdade de direitos, recusa da desigualdade do tratamento. Na recusa à igualdade de direitos e ao reconhecimento das diferenças (base dos direitos humanos) é que aparecem o bullying, a violência da discriminação e o preconceito (SCHILLING, 2013; SCHILLING; ANGELUCCI, 2016).

0 terceiro elemento apontado é exatamente que, com a mediação da palavra, com a possibilidade da palavra que permite uma aproximação à alteridade, é possível a quebra de significados cristalizados: é uma chance de superar dualidades que nos cercam: bandido/ cidadão honesto, normal/anormal, amigo/inimigo.

Em Modernidade e ambivalência, Bauman (1999) trabalha centralmente com as questões contemporâneas que nos fazem tentar construir uma ordem que elimine o diferente, as diferenças. Fala das classificações, dizendo que classificar é dar ao mundo uma estrutura, manipular suas probabilidades, limitar a casualidade.

0 ideal que a função nomeadora/classificadora se esforça por alcançar é uma espécie de arquivo espaçoso que contém todas as pastas que contém todos os itens do mundo - mas confina cada pasta e cada item num lugar próprio, separado. (BAUMAN, 1999, p. 10).

Classificar supõe o ato de incluir e excluir e isso implica coerção e violência. Esta é uma operação constante da modernidade que é sempre incompleta e parcialmente fracassada, pois a ambivalência permanece.

Dentre a multiplicidade de tarefas impossiveis que a modernidade se atribuiu e que fizeram dela o que é, sobressai a da ordem (mais precisamente e de forma mais importante, a da ordem como tarefa) como a menos possível das impossíveis e a menos disponível das indispensáveis com efeito, como o arquétipo de todas as outras tarefas, uma tarefa que torna as demais meras metáforas de si mesmas. (BAUMAN, 1999, p. 12, grifos do autor).

Há, assim, nesse esforço por construir a ordem, por controlar a desordem e o caos, um trabalho incessante de classificação das coisas. Esse esforço por exterminar a ambivalência (produto do esforço classificatório) produz a intolerância: “[...] a intolerância é, portanto, a inclinação natural da prática moderna - exige a negação dos direitos e das razões de tudo que não pode ser assimilado - a deslegitimação do outro" (BAUMAN, 1999, p. 16).

Em todos os casos, porém, há resistências às definições e às cristalizações dos lugares que poderão ser ocupados. A justiça restaurativa, em seu trabalho de escuta e encontro com a alteridade, propõe uma descristalização das classificações que permeiam as relações, permitindo a ocupação de algum outro lugar.

0 que o documento do CDHEP propõe é que se tente remover as certezas que nos cercam, as classificações em que estamos encaixados, que se tente estranhar esses lugares fabricados e se possa convidar o sujeito a ocupar um outro lugar. Este terceiro ponto mereceu nossa atenção de forma especial, pois é um dilema da educação: como 
educar na igualdade e na diferença? É possível educar na diferença? Duschatzky e Skliar (2001) pensam a respeito do lugar do outro na educação. Este costuma ocupar três lugares possíveis: o outro como fonte de todo o mal; o outro como sujeito pleno de um grupo cultural; o outro como alguém a tolerar. Trata-se de recusar os lugares encaixados, os lugares cristalizados. Se a cultura é “[...] um território de diferenças que precisa de permanentes traduções, o problema crucial é quem traduz a quem (ou quem representa a quem) e através de quais significados políticos" (BHAHBA, 1994 apud DUSCHATZKY; SKLIAR, 2001, p. 122), a pergunta é:

Será impossível a tarefa de educar na diferença? Felizmente, é impossível educar se acreditamos que isto implica formatar por completo a alteridade, ou regular sem resistência alguma, o pensamento, a língua e a sensibilidade. Porém parece atraente, pelo menos não para poucos, imaginar o ato de educação como uma colocação à disposição do outro, de tudo aquilo que o possibilite de ser distinto do que é, em algum aspecto. Uma educação que aposte transitar por um itinerário plural e criativo, sem regras rígidas que definam os horizontes de possibilidade. (DUSCHATZKY; SKLIAR, 2001, p. 137).

Aqui há uma aposta da justiça restaurativa, que não incide especialmente na questão da indisciplina ou da rebeldia de adolescentes e tenta um trabalho (mesmo que limitado) de permitir que, por meio da palavra e do reconhecimento da alteridade, estes ocupem um outro lugar, desconstruindo, assim, significados cristalizados.

\section{Entrevistas com os/as professores/as que iniciam trabalhos com justiça restaurativa nas escolas}

\section{Contexto da coleta dos dados}

As entrevistas foram realizadas entre os dias 25 de junho e 01 de julho de 2015, nas Unidades Escolares I e II, ambas localizadas no Jardim Ângela, zona sul de São Paulo. 0 critério de seleção dos entrevistados foi a sua participação em curso de formação sobre justiça restaurativa e círculos de paz, oferecido pelo CDHEP (Centro de Direitos Humanos e Educação Popular de Campo Limpo), organização não governamental que atua há mais de três décadas na região. Em 2014, essa formação foi oferecida na sede do CDHEP, quando foi acordado, junto à equipe gestora e supervisão de ensino dessas unidades escolares, que, durante o ano letivo de 2015, essa formação seria oferecida nos horários de JEIF (jornada especial integral de formação). Ressalta-se que, em ambos os casos, a implementação da justiça restaurativa é um dos propósitos dos projetos políticopedagógicos dessas unidades escolares.

Dos/as participantes, quatro são homens e quatro são mulheres. Embora três dos/ as docentes tenham entre 40 e 50 anos, as idades vão de 25 a mais de 50 anos. Com relação às disciplinas, temos: educação física, língua portuguesa, inglês, matemática, geografia, alfabetização. 
Quadro 1 - Disciplina em que atua

\begin{tabular}{ccc}
\hline Entrevistado & Disciplina em que atua \\
\hline 01 & Educação física \\
\hline 02 & Língua portuguesa / Inglês \\
\hline 03 & Matemática \\
\hline 04 & Inglês \\
\hline 05 & Geografia \\
\hline 06 & Elfabetização / professora polivalente. Leciona até o $77^{\circ}$ ano \\
\hline 07 & Alfabetização / professora polivalente. Leciona para o ensino fundamental e EJA, além de responsável pela \\
\end{tabular}

Fonte: Elaborado pelas autoras.

Também é relevante que todos/as os/as docentes entrevistados/as possuem um vínculo efetivo na SME. Foi devido a isso, além do interesse de cada um, que a equipe gestora os/as selecionou para as formações de justiça restaurativa.

Os dados sobre o tempo de formação revelam que os/as docentes se formaram até os 25 anos, menos um/a entrevistado/a que se formou mais tardiamente. Não menos importante é a constatação de que, exceto a entrevistada cinco, que se formou em Universidade Pública no Estado do Ceará - de onde é natural - todos/as os/as outros/as docentes tiveram suas formações em Universidades Privadas. Dos/as oito entrevistados/as, sete já possuem pósgraduação: um stricto sensu (mestrado - entrevistado 01) e seis especializações (entrevistados/ as 02, 03, 05, 06, 07 e 08). Somente o entrevistado 04 afirmou que não tinha especialização alguma, mas que pretendia continuar sua formação em 2016. Note-se que todas as pósgraduações citadas ocorreram em Universidades Privadas.

\section{Conhecimento anterior da justiça restaurativa e sobre o trabalho dos/as professores/as mediadores/as}

A primeira questão versou sobre o conhecimento anterior da justiça restaurativa e da política estadual de implementação, nas escolas, da figura dos/as professores/as mediadores/as. Todos/as os/as professores/as já tinham ouvido falar tanto da justiça restaurativa como dos/as professores/as mediadores/as e consideram sua atuação muito importante, mesmo tendo dúvidas sobre como acontece na prática das escolas:

0 professor mediador, ele vai ter um tempo que talvez o professor em sala de aula não tenha. Então, ele vai ter mais tempo mesmo para discutir, saber o que aconteceu, o que aconteceu, quais eram os sentimentos que estavam envolvidos. Enquanto a gente, professor, às vezes a gente deixa, corta a situação pela metade, porque a gente tem que cuidar dos outros que ficaram. E às vezes depois quando a gente vai conversar, parece que a coisa já tá meio esquecida, já não tem tanta importância. (P5). 
0 professor mediador é interessante porque ele fica responsável por essa especificidade dentro da escola, de manter a ordem, não a ordem no sentido regrado da palavra, mas de estabelecer a harmonia mesmo. (P2).

[...] a ideia ela é bacana. Eu acho que as escolas, elas deveriam efetivar de fato, vamos dizer, as atividades do professor mediador, porque o que hoje acontece é o seguinte: existe o professor mediador nas escolas, mas esse professor, ele praticamente não exerce as atividades dele como está escrito lá no papel. Se ele exercesse, eu acho que nós íamos colher bons frutos dentro da escola, em nível de disciplina dos alunos [...] quando acontece algum conflito dentro do ambiente escolar, ele vai lá, conversa um pouco com os alunos envolvidos e ponto final. (P4).

Mesmo a experiência dos/as professores/as mediadores/as sendo uma experiência da rede estadual de ensino, e estamos conversando com professores da rede municipal, há um conhecimento de "ouvir falar". Porém, todos/as ressaltam sua importância, porque seria uma possibilidade de conversar. Não há uma vinculação muito precisa do PMEC ou da figura do/a mediador/a na justiça restaurativa em seu trabalho com as questões centrais da escola, seus conflitos recorrentes, projetos coletivos, proposição de ações visando a aprendizagem. P4 é o entrevistado que melhor conhece a função e seus dilemas, as dificuldades que estes/as professores/as têm em relação à direção e gestão da escola e a indefinição de seu papel. Há uma ideia recorrente de que a presença do/a professor/a mediador/a é importante e que trabalhará com “[...] manter a ordem, não a ordem no sentido regrado da palavra, mas de estabelecer a harmonia mesmo" (P2).

\section{Expectativas}

Perguntados sobre suas expectativas em relação à justiça restaurativa, os/ as professores/as são unânimes em afırmar que são práticas interessantes, podem ser facilitadoras, mesmo concordando que não é algo que acontecerá no curto prazo.

Sempre quando tem alguma organização que não é da escola que vem para a escola, eu tenho algumas ressalvas, eu fico meio com o pé atrás. Porém, eu acho que como, por exemplo, a Fundação Lemann, Amigos da Escola, a Fundação Itaú, e assim por diante. É, por que parece que - a gente fica aqui 800 horas relógio e 200 dias letivos - e parece que a gente não faz nada e quando eles chegam aqui parece que mudam a realidade e não se considera o trabalho do professor. Mas quando chega um projeto que quer dialogar com os professores, [...], mas tem uma metodologia implementada, eu acho que é interessante. [...] quer sensibilizar com a história de vida que o professor tem ou que já teve no passado com as questões de injustiça que ele teve [...]. $\mathrm{Eu}$ acho que a ideia é entender por que que esses conflitos acontecem [...], mas eu penso numa relação em que o professor e o aluno possam respeitar esse espaço, respeitar as pessoas que aqui estão. Penso, mas eu acho que ainda assim é meio utópico, ainda mais no momento que a gente vive. (P1, grifo nosso). 
$\mathrm{Na}$ verdade, a justiça restaurativa, a meu ver, ela é uma esperança para a gente tentar resolver alguns conflitos que existem dentro do ambiente escolar, só que acho que isso demanda um certo tempo... (P4).

Eu já sou bastante otimista, eu acho que quando a gente trabalha mesmo com essa ideia de trabalhar em círculo, que todo mundo se olhe nos olhos, que passa a perceber o que o outro sente quando é agredido, eu acho que melhora, melhora o ser humano. Melhora os aspectos humanos mesmo do respeito ao outro. (P5).

Eu espero que funcione de verdade, eu tive uma experiência pelo CDHEP na minha sala, a gente fez um círculo lá [...] porque assim, a minha sala, eu peguei uma turma extremamente nervosa, eles brigam o tempo todo por tudo. Eles querem se bater, qualquer coisa é motivo para empurrar e eu pedi para elas (do CDHEP) irem lá. Elas foram e fizeram... e pediram para eles fazer um desenho de como que eles eram quando estavam com raiva, e a maioria deles desenhou demônios. E a gente colocou lá na parede e depois eles ficaram: "Nossa! Olha como eu sou, olha como eu sou professora. Eu sou feio, né? Olha como eu fico quando eu tô com raiva”. [...]. Eu comecei a pensar muito nisso: "Meu Deus, olha o que estou fazendo na sala de aula também, né? Será que o que eu estou fazendo está dando resultado positivo pra esses alunos? Então, acho que é uma coisa boa”. (P8).

Não há muita crença em que "resolva problemas", mas pode ser um facilitador do convívio escolar. Trata-se de uma percepção parecida à da introdução da mediação de conflitos na escola. É uma tentativa, algo bom, que deve ser tentado. Um impacto da formação recebida e que pode ser sentida nas falas dos/as professores/as é de que é algo que muda a sensibilidade, faz pensar, rever seu lugar: "[...] ela traz assim conceitos que você pode mudar a sua própria postura. Não diria mudar, mas transformar ou modular, se reeducar em relação a certas posturas." (P2).

Haveria, assim, um potencial reflexivo interessante que produziria efeitos nas práticas. Poderia, ao modular modos de olhar e posturas, ter um efeito sobre os conflitos, inclusive os violentos. Também parece ter se ampliado o olhar sobre o que é ou não violência, a existência de violências que se sobrepõem e se intercruzam. Há, assim, o relato de jogos de olhares, do ver e do ser visto, que pode se relacionar a um dos objetivos da justiça restaurativa, o de lidar com a alteridade e mudar significados cristalizados.

\section{Quais são os casos?}

Dada a importância da verificação de quais casos seriam objeto de ações da justiça restaurativa, quem seriam os sujeitos a serem trabalhados e quais os conflitos, colocaremos todos os casos relatados pelos/as professores/as. Nas entrevistas, não é claro quem seria o usuário dos círculos restaurativos e da justiça restaurativa nas escolas. Professores? Alunos? Em que medida, em quais situações? Esse é um impasse importante nessa discussão, nessa tentativa de lidar (amenizar) com os conflitos na escola, de resolver conflitos. 


\title{
A guerra de frutas
}

\begin{abstract}
Vou dar um exemplo de ontem, que aconteceu aqui na escola. Então ontem, a gente estava no pátio na hora do almoço e eu fui lá almoçar com as crianças e tinha mexerica e eles começaram a jogar a casca, jogar mexerica um no outro. Eu acho que aí é um ponto de problematização para se construir algumas rodas de diálogo pra se ter um convívio melhor que não... que a gente não degrade esse espaço e nem o outro, de uma certa maneira, que se construa métodos de convivência nesses espaços, para que os alunos criem uma certa consciência que aquele espaço é dele [...]. Acho que o respeito ao bem comum, ao espaço público, o respeito à diferença do outro, o convívio com a diferença. (P1).
\end{abstract}

Os casos que seriam objeto da atenção da justiça restaurativa em seus círculos restaurativos merecem especial atenção. 0 primeiro caso apresentado, o da "guerra de frutas", trata de um evento envolvendo alunos e alunas na hora da merenda escolar. É um caso que sugeriria um limite, uma conversa, ou, como a professora também sugere, um trabalho sobre o uso do espaço público, o uso do que é um bem público. Seria objeto, assim, de uma ação educativa, geral, que não necessariamente faria sentido em um círculo restaurativo.

\section{E o estudo?}

$\mathrm{Ah}$ ! Eu acredito que aquelas pessoas, alguns estudantes que vêm para a escola, e infelizmente, o estudo fica como último item do tópico. Não no caso assim de fazer baderna ou alguma coisa nesse sentido, mas de que realmente, não entenda o âmbito escolar enquanto o âmbito para estudo. (P2).

$\mathrm{Na}$ seguinte entrevista, encontramos outro caso que seria encaminhado à justiça restaurativa: o dos/as alunos/as que não se interessam pelo estudo, que não querem estudar. Novamente, essa seria uma questão para um círculo restaurativo ou se trataria de propor uma ação pedagógica na escola, uma discussão na escola sobre como estão as aulas, algo a ser tratado pelos professores em sua avaliação, nos horários pedagógicos e no projeto pedagógico da escola? Possivelmente, uma ação de formação e um projeto de participação para os/as professores/as seria mais interessante que um círculo restaurativo. É interessante pensar quem estaria nesse círculo: os/as alunos/as desinteressados/as seriam as vítimas e o/a agressor/a seria a escola desinteressante?

\section{Desrespeito ao/à professor/a!}

Desrespeitado... eu me senti desrespeitado realmente. Eu vejo que toda ação tem reação. Então, a coisa que eu vejo muito importante numa sala de aula, por exemplo, é a disciplina. Então, num círculo a gente teria que discutir essa disciplina, um modo de amenizar o tumulto, amenizar os conflitos que não são poucos. (P3). 
P3 acredita que o círculo deveria contemplar os/as alunos/as indisciplinados/as, que desacatam e desrespeitam o professor. Na entrevista, queixa-se da posição da direção da escola, muito "a favor da justiça restaurativa" e pró-aluno/a e que não considera o sofrimento do/a professor/a. No caso, nesse círculo, o/a agressor/a é o/a aluno/a e a vítima é o/a professor/a. 0 círculo poderia dar conta desse sofrimento do/a professor/a, que poderia ser verbalizado, que poderia, assim, sensibilizar o/a aluno/a agressor/a. Considera que haveria mais justiça, pois um dos lados, que aparentemente também não é ouvido na escola, é o do/a professor/a. Haveria, assim, uma escuta desse sofrimento.

\section{Pobreza e crime}

[...] tem um garoto que ele é extremamente pobre, então ele vive desmotivado, não quer saber de estudar. Ele tem doze anos e ele falta muito na escola, ele vive em conflitos com os colegas, quer bater em todo mundo, arruma briga o tempo todo. 0 professor vai conversar e ele não ouve o professor, não quer saber do professor. Ele já acha que já sabe de tudo, já acha que pode tudo, eu sinto que ele está assim envolvido na criminalidade e é assim, eu acho que é muito também por falta de condições mesmo, porque a família dele é bem pobre mesmo e não tem condições de dar nada para ele. Então eu sinto que ele tá enveredando para o caminho do crime. Ele está no sexto ano, não está defasado. (P4).

P4 chama a atenção para a importância do círculo nas questões de indisciplina, mas traz um caso mais complexo, que envolve, a partir de uma situação descrita de pobreza, a adesão de uma criança ao mundo do crime. Esta adesão teria como pano de fundo tanto o desinteresse da criança pelo estudo como a raiva e a indisciplina. Propõe que o círculo, ao criar um espaço de escuta e diálogo, permitiria que a criança problematizasse essa adesão. 0 relato mostra que há uma distância e um desconhecimento entre alunos/as e professores/as; há representações mutuamente cristalizadas que poderiam ser mudadas nesse encontro. 0 círculo poderia ajudar a quebrar essas representações e permitir que as pessoas ocupassem outro lugar.

\section{Agressão, gênero, pobreza!}

Olha, tem um caso que eu acho que deveria ter sido tratado num círculo restaurativo, de uma agressão verbal que um colega recebeu sobre a questão de opção sexual, e a menina foi extremamente agressiva com as palavras e ficou uma coisa muito mal resolvida, que houve até um afastamento dos dois da escola, assim, eles mesmo... sabe? [...] No primeiro, eu acho que tem que pensar essa questão de gênero, respeitar o gênero, acho que foi o foco do problema. No segundo caso, a gente já até tentou resolver, que é questão de higiene pessoal, que gerou todo um atrito aí e uma exclusão de um colega. A gente já conversou com a família. A gente tá esperando que... Eu não sei o que fazer... Como trabalhar com ele num círculo? (P5). 
P5 nos traz dois relatos de intolerância vinculados à orientação sexual, de agressão verbal e de assédio. Esses poderiam ser casos para tratar em um círculo, para tentar modificar as relações entre as vitimas e os agressores, mas também poderiam ser temas a serem tratados na escola, na sala de aula, serem objeto de uma ação pedagógica. As duas possibilidades não são excludentes. Um dos casos foi resolvido com violência, com um grupo de apoio da menina dando uma surra no menino que a assediou. 0 menino parou de ir à escola. Essa é uma situação muito grave: pode-se pensar, sim, em um caso para um círculo, mas com a presença dos meninos agressores. Aparentemente, a escola não desenvolveu nenhuma ação. Após estes casos, que poderiam comportar o trabalho de um círculo restaurativo (ou ao menos uma conversa com os envolvidos!) há o relato de um caso de um menino que cheira mal. São apresentadas as alternativas que foram tentadas para dar conta da questão, na sala de aula e com a família. Há uma dubiedade nas queixas à família, pois esta não chega a compreender do que se trata.

\title{
Intolerância religiosa
}

Eu acho que uma coisa que tá bem em evidência são as intolerâncias religiosas, que isso está bem, eu acho que as pessoas tão... pregam muito a questão de Deus, de Deus, de Deus, mas fazem totalmente ao contrário. Eles fazem as coisas de forma que Deus não aceitaria, porque cada um tem que respeitar, independente de sua religião, cor, raça, credo... tem que respeitar as pessoas. A intolerância tá demais hoje no Brasil. (P6).

P6 apresenta uma preocupação com o discurso religioso que termina por produzir atitudes de preconceito e desrespeito. Cabe novamente perguntar se esse seria um caso de um círculo restaurativo ou de promover um debate, uma campanha contra a intolerância, um evento sobre as religiões e sua relação com a paz? Novamente há, no relato, a percepção de que o/a professor/a vive situações extremamente difíceis e que geram sofrimento e é o/a professor/a aquele/a que não encontra um lugar para trabalhar essas angústias. Talvez daí a proposta de um círculo. Um lugar onde o/a professor/a possa falar, onde possa ser ouvido/a.

\section{Desrespeito entre colegas!}

\begin{abstract}
0 que aconteceu comigo, então vou falar um que aconteceu comigo: eu estava dando aula para um sexto ano e... Uma menina me pediu para ir ao banheiro, ela foi ao banheiro, quando ela voltou, eu tinha separado um garoto da sala de um outro, porque os dois juntos estavam pegando fogo, para continuar a atividade. Aí, esse garoto virou para a menina e falou assim: "Nossa, você foi muito rápido! Não deu tempo de limpar..." aí, eu peguei, olhei para ele e falei assim: "Você agiu com desrespeito a mim, à sua amiga e a todos da sala". (P7).
\end{abstract}

P7 narra, com indignação, um caso de desrespeito com uma menina. No caso, o mais interessante é que a situação parece ter ferido principalmente a professora, pois a menina não estava disposta a continuar com a situação. Um círculo restaurativo poderia 
ser criado para restaurar o dano produzido. Novamente, essa é uma questão da escola, algo que a escola pode e deve trabalhar pedagogicamente, discutindo relações de gênero.

\section{Ofensas}

Tá... agressão, claro que às vezes não é agressão só física, é agressão verbal também. Eu acho que assim, quando há já uma sequência de atitudes, assim, de alunos. Eles vêm, ofende o outro, no dia seguinte, ofende de novo. Aí, quando já há uma sequência de atitudes eu acho que já tem que mediar. (P8).

P8 apresenta uma fala muito interessante, pois considera que, se a justiça restaurativa fosse aplicada em quem ofende, toda a escola deveria passar pela justiça restaurativa e não haveria tempo possível para fazer isso com todos. É evidente que, se é algo que ocorre com todos e contra todos o tempo todo, as ações possíveis são globais e são pedagógicas, são de toda a escola: campanhas, debates, educação. Se o objeto da justiça restaurativa se encontra tão diluído, fica difícil imaginar quem, como, quando aplicar um círculo restaurativo.

\section{Uma certa conclusão e novas perguntas: a escola ficará mais justa com a introdução da justiça restaurativa?}

Os depoimentos apresentados e analisados revelam os impasses que cercam a educação brasileira e que hoje se reiteram, tendo em vista o atual momento político em que correntes autoritárias e excludentes se fazem presentes: Como se educa? 0 que é educar? Quem pode ser educado? Quando? Por quem? Educaremos para a liberdade, mas também domesticaremos... Educaremos pelo medo? Acalmaremos e tranquilizaremos ou resolveremos as questões sociais que estão emoldurando os problemas mencionados? 0 que pode a escola fazer?

Nestes depoimentos, as tensões que permeiam o cotidiano escolar estão todas presentes retratando um certo desamparo de alunos/as e o desamparo de professores/as. Retratando, também, sua potência e força, a vontade de mudar que os/as anima. Como ser professor/a, hoje? Como ser aluno/a, hoje? Qual é o lugar da disciplina, qual é o lugar da diferença, qual é o lugar do currículo?

A última pergunta, a partir das inquietações que nos fizeram ir a campo, tentando pensar o quê da justiça, o quem da justiça, o como da justiça, foi exatamente sobre o possível impacto desta introdução da justiça restaurativa nas escolas.

Quatro entrevistados/as consideram que a introdução da justiça restaurativa nas escolas tornaria a escola mais justa, mesmo alegando motivos diversos: ajudaria a resolver as questões da disciplina, tornando o trabalho do/a professor/a possível, porque apostaria no diálogo, na conversa, porque aumentaria a possibilidade de uma autorreflexão, de um autoconhecimento.

Os/As demais, formando um grupo também heterogêneo, apresentam algumas dúvidas, colocam alguns limites nessa capacidade da escola ser mais justa: a justiça restaurativa, em uma opinião, não traria necessariamente mais justiça pois não lida com isso e sim com a amenização do conflito; atuaria para tranquilizar, "harmonizar" o 
ambiente. A justiça restaurativa "não veio para salvar", pois não considera suficientemente o sofrimento do/a professor/a, diz um entrevistado. Assim, a justiça restaurativa também comportaria uma injustiça: em relação ao/à professor/a, atuaria com "dois pesos e duas medidas”, como dizem P2 e P4, que também consideram que ela não é totalmente justa em relação à vítima. $\mathrm{P} 1$, por exemplo, mostra os limites da escola justa em relação à tolerância a ao convívio com a diferença. Sustenta que a justiça restaurativa pode ajudar, mas que o entorno não colabora, ao fomentar a intolerância religiosa, por exemplo. Chama a atenção para a possibilidade, ao olhar o/a outro/a e escutar o/a outro/a, de que se trabalhe com um currículo mais justo: esse seria um currículo que abordaria as diferenças.

Estas diferenças são muito relevantes, mostrando quão difícil é a discussão sobre o que seria justo, o que seria uma escola justa. Há uma certa esperança em relação à introdução da justiça restaurativa, mas não há a ilusão de que possa modificar profundamente as relações escolares: talvez serviria para amenizar o que se vive nessa instituição. Poderia, quem sabe, tornar o cotidiano mais possivel de viver.

[...] eu acho que é um início de desconstrução sobre a ótica de justiças, sobre a ótica do outro, sobre a ótica da diferença dentro da escola e do respeito ao espaço público, ao professor, ao trabalho do professor, eu acho que é um início. (P1).

Porém, eu não acredito que ela veio pra salvar. (P2).

Para mim não, a justiça restaurativa é... digamos que é... um elemento moderador de um determinado conflito, de um determinado ambiente, tá? Não comete uma injustiça nem uma justiça, certo? Então é isso que eu acho. (P4).

[...] eu tenho esperança que sim, eu não tenho certezas, mas esperança, otimismo que isso possa realmente ocorrer, que torne a escola mais justa, porque eu acho que a gente ainda é um espaço muito justo, por conta dessa correria mesmo que a gente vive. (P5).

Eu acredito que fica mais justa, porque a gente passa a ouvir o outro por essa forma de justiça. (P8).

Como reiteradamente visto em diversas pesquisas, as angústias que cercam a função docente na atualidade estão todas presentes nestas falas emocionadas e esperançosas, com todas as suas diferenças e matizes. Não há lugar para a indiferença frente a depoimentos tão preciosos e tão reveladores dos impasses e possibilidades das políticas públicas envolvendo justiça e educação. Há uma frase que funciona como uma síntese: "tudo é um pouco dolorido" (SCHILLING, 2018). Como uma escola pode ser justa? Alguns caminhos estão sendo traçados por estes milhares de homens e mulheres, professores e professoras das redes públicas do nosso país. 


\section{Referências}

ARENDT, Hannah. Responsabilidade e julgamento. São Paulo: Companhia das Letras, 2004.

BOONEN, Petronella Maria. A justiça restaurativa, um desafio para a educação. 2011. Tese (Doutorado) - Universidade de São Paulo, São Paulo, 2011.

BAUMAN, Zygmunt. Modernidade e Ambivalência. Rio de Janeiro: Zahar, 1999.

BAUMAN, Zygmunt. Em busca da política. Rio de Janeiro: Zahar, 2000.

CDHEP. Centro de Direitos Humanos e Educação Popular de Campo Limpo. Justiça restaurativa juvenil: conhecer, responsabilizar-se, restaurar São Paulo: CDHEP, 2014. Relatório final do projeto. Novas metodologias de justiça restaurativa com adolescentes e jovens em conflito com a lei.

DERRIDA, Jacques. Força de Lei. São Paulo: Martins Fontes, 2007.

DUSCHATZKY, Silvia; SKLIAR, Carlos. 0 nome dos outros: narrando a alteridade na cultura e na educação. In: LARROSA, Jorge; SKLIAR, Carlos. Habitantes de Babel: políticas e poéticas da diferença. Belo Horizonte: Autêntica, 2001. p. 119-138.

EDNIR, Madza (org.). Justiça e educação em Heliópolis e Guarulhos: parceria para a cidadania. São Paulo: CECIP, 2007. Disponível em: www.mpsp.mp.br/portal/page/portal/Cartilhas/justica-e-educacao_ web.pdf. Acesso em: 11 set. 2019.

EWALD, François. Foucault, a norma e o direito. Lisboa: Vega, 1993.

FRASER, Nancy. Escalas de justiça. Barcelona: Herder, 2008.

HELLER, Agnes. Além da justiça. Rio de Janeiro: Civilização Brasileira, 1998.

MELO, Eduardo Rezende. Justiça restaurativa e comunitário em São Caetano do Sul: aprendendo com os conflitos a respeitar direitos e promover a cidadania. Rio de Janeiro: CECIP, 2008.

O'MALLEY, Pat. Riesgo, neoliberalismo y justicia penal. Buenos Aires: Ad-Hoc, 2006.

PENIDO, Egberto de Almeida. "Justiça e educação: parceria para a cidadania" em Heliópolis/SP: a imprescindibilidade entre justiça restaurativa e educação. São Paulo, 2009. Disponível em: https://www. tjsp.jus.br/Download/CoordenadorialnfanciaJuventude/Pdf/JusticaRestaurativa/Artigos/ArtigoJR-IOB.pdf. Acesso em: 12 set. 2019.

RICOEUR, Paul. 0 justo. São Paulo: Martins Fontes, 2008.

SCHILLING, Flávia. Educação e direitos humanos: percepções sobre a escola justa. São Paulo: Cortez, 2014. 
SCHILLING, Flávia. Educação em direitos humanos: reflexões sobre o poder, a violência e a autoridade na escola. Universitas Psychologica, Bogotá, v. 7, n. 3, p. 691-700, sep./dic. 2008.

SCHILLING, Flávia. Igualdade, desigualdade e diferenças: o que é uma escola justa? Educação e Pesquisa, São Paulo, v. 39, n. 1, p. 31-48, 2013.

SCHILLING, Flávia. Mediação de conflitos, justiça restaurativa: caminhos para uma escola mais justa? ETD: Educação Temática Digital, São Paulo, v. 20, n. 2, p. 325-342, 2018. Disponível em: https://periodicos. sbu.unicamp.br/ojs/index.php/etd/article/view/8650506/17899. Acesso em: 12 set. 2019.

SCHILLING, Flávia; ANGELUCCI, Carla Biancha. Conflitos, violências, injustiças na escola? Caminhos possíveis para uma escola justa. Cadernos de Pesquisa, São Paulo, v. 46, n. 161, p. 694-715, set. 2016.

Recebido em: 28.05.2020

Revisado em: 30.06 .2020

Aprovado em: 20.10 .2020

Flávia Schilling é professora sênior da Faculdade de Educação da Universidade de São Paulo. É pesquisadora do CNPq (2012 a 2020) e integrante do Grupo de Pesquisas em Direitos Humanos, Memória, Política e Democracia do Instituto de Estudos Avançados da USP.

Daniele Kowalewski faz pós-doutorado em educação sobre os centros de educação em direitos humanos em São Paulo e é bolsista CAPES-PNPD. Ministra, na Faculdade de Educação da USP, a disciplina "Multiculturalismo, direitos humanos e educação: temas contemporâneos" e presta assessoria à Secretaria Municipal de Educação para assuntos concernentes à educação integral. 